\title{
Bringing Service Interactions Into Focus: Prevention- Versus Promotion-Focused Customers' Sensitivity to Employee Display Authenticity
}

\author{
Andreas T. Lechner' (i) and Frank Mathmann ${ }^{2}$
}

\begin{abstract}
Despite growing managerial interest in frontline employee behavior, and in display authenticity specifically, customers' heterogeneous reactions to authentic displays have received little scholarly attention. Drawing on emotion as social information theory, we investigate the role of motivational orientations (i.e., regulatory focus) in customer reactions to authentic displays. The findings show that inauthentic displays have stronger negative effects on service performance for prevention-focused than for promotion-focused customers. A dyadic field study details these effects in terms of tipping, and three experiments provide further evidence by experimentally manipulating authenticity and regulatory focus. The conditional effect of authenticity on service performance also is mediated by inferred deception. Specifically, prevention-focused customers interpret inauthentic emotion displays as more deceptive than promotion-focused customers do. Managers should prime customers' promotion focus using marketing communications before the service delivery when inauthentic displays are likely as well as consider customers' regulatory focus when designing authenticity training for employees.
\end{abstract}

\section{Keywords}

authenticity, emotional labor, regulatory focus, service performance, tipping

Advances in automation in fields such as food delivery (e.g., Spyce Kitchens) and luggage handling (Sheraton Hotels, San Gabriel; Bird 2018) have limited the opportunities for service workers who rely on tips to secure their livelihoods by providing superior performance. In this setting, the human aspect of service delivery that still involves frontline employees (FLEs) has grown ever more important, prompting managerial interest in aspects such as the authenticity of positive emotion displays by FLEs (Taylor 2013). Service firms often define specific FLE behaviors to ensure service performance and encourage authenticity of positive displays (Walmart 2018). In various industries, display authenticity even constitutes a key strategic goal and source of competitive advantages (e.g., Kroger, Schuster 2012; The Ritz-Carlton, Solomon 2015) that may become deeply rooted within an organizational culture (Best Buy 2018; Hard Rock Cafe International 2017). However, current insights into how customers react to display authenticity, as indicated by behaviors such as tipping, are limited (Grandey and Gabriel 2015).

Rather, prior research on display authenticity mostly pertains to its antecedents and effects for employees. For example, extant research notes individual differences among employees (e.g., Dahling and Johnson 2013) and the effects of situational variables (e.g., Diefendorff, Croyle, and Gosserand 2005) on authenticity. It also covers the effects of authenticity on employee outcomes such as burnout and job satisfaction (for recent meta-analyses, see Hülsheger and Schewe 2011; Kammeyer-Mueller et al. 2013; Mesmer-Magnus, DeChurch, and Wax 2012; Wang, Seibert, and Boles 2011). However, we know of few studies that deal with customer reactions to display authenticity and the factors that might explain their potential heterogeneity (Hennig-Thurau et al. 2006). A few initial studies report positive effects of display authenticity on service performance (Gountas, Ewing, and Gountas 2007) but also considerable heterogeneity (Andrzejewski and Mooney 2016; Grandey et al. 2005; Wang, Seibert, and Boles 2011). Although customers are at the heart of service delivery, no studies address individual differences among them (cf. Groth, Hennig-Thurau, and Walsh 2009); instead, they tend to deal with employee or customer-employee dyadic factors such as

\footnotetext{
'Faculty of Business and Economics, University of Augsburg, Augsburg, Germany

${ }^{2}$ QUT Business School, Queensland University of Technology, Brisbane, Australia

\section{Corresponding Author:}

Andreas T. Lechner, Faculty of Business and Economics, University of Augsburg, Universitaetsstr. 16, 86159 Augsburg, Germany.

Email: andreas.lechner@mailbox.org
} 
employee personality (e.g., Chi et al. 2011) and store busyness (Grandey et al. 2005). Accordingly, several scholars call for research on customer factors that can explain heterogeneity in the positive effects of FLE display authenticity (Grandey and Gabriel 2015; Yagil and Shnapper-Cohen 2016).

Considering the significance of positive display authenticity for both practice and theory, we seek to address these gaps and contribute to extant literature in three important ways. First, drawing on emotion as social information (EASI) theory (van Kleef 2009), we consider heterogeneity in the effects that FLEs' display authenticity has on customers (MesmerMagnus, DeChurch, and Wax 2012). This theory proposes that heterogeneous effects of authenticity can be explained by an "observer's motivation and ability to process the information represented in these expressions" (van Kleef 2009, p. 186). Groth, Hennig-Thurau, and Walsh (2009) investigate the role of customers' ability but not the influence of their motivation on their immediate reactions to display authenticity. We propose that customers' regulatory focus (Higgins 1998) shapes their inferences of display (in)authenticity, according to whether they adopt a prevention focus, manifesting a concern for safety and security, or a promotion focus, which implies a concern for growth (Higgins 1998, 2012). We show that inauthentic displays exert stronger negative effects on service performance when customers have a predominant prevention (vs. promotion) focus. That is, customers' regulatory focus can explain some of the heterogeneity in their reactions to display authenticity (Mesmer-Magnus, DeChurch, and Wax 2012; Wang, Seibert, and Boles 2011).

Second, we extend regulatory focus theory (Higgins 1998) to the study of interpersonal emotions. Most research into the link between regulatory focus and emotions cites intra- rather than interpersonal effects (Brockner and Higgins 2001; Higgins and Cornwell 2016; Higgins, Shah, and Friedman 1997; Yen, Chao, and Lin 2011), though regulatory focus clearly might shape people's reactions to others' emotions (van Doorn, van Kleef, and van der Pligt 2014). This consideration is especially critical, given the increasing interest in and acknowledgement of the importance of the social functions of emotional displays (Keltner and Haidt 1999; van Kleef 2014). We therefore demonstrate, for the first time, that a prevention (vs. promotion) focus shapes customer reactions to the inauthenticity of others' emotion displays, rather than just experiences of their own emotions. This finding promotes further theory development, by establishing a critical integration between regulatory focus theory and emergent research on the social consequences of emotional displays (van Kleef, de Dreu, and Manstead 2010).

Third, we investigate the mechanisms by which authenticity affects service performance in relation to prevention-focused customers. Building on EASI theory (van Kleef 2014), we test for mediation by both affective reactions and cognitive inferences such as inferred deception (Grandey et al. 2005; van Kleef 2009). We find evidence of a cognitive but not an affective pathway. Specifically, inauthentic displays exert stronger negative effects on service performance among preventionfocused (vs. promotion-focused) customers because they interpret inauthentic displays as more deceptive. This finding extends authenticity literature and adds nuance to prior marketing and psychology findings that suggest customers generally construe inauthentic displays as persuasion tactics and thus as manipulative (Grandey et al. 2005; Gunnery and Hall 2014).

In addition to this threefold contribution to theory, we offer notable implications for service managers, in line with the recognition that regulatory focus explains when display inauthenticity will affect customers. For example, priming a promotion as opposed to a prevention focus (e.g., with product descriptions, Study 4) attenuates the effect of inauthentic displays on service performance. If service managers can get customers to think like promotors, they can attenuate the negative effects of inauthentic emotion displays, at least until they can enhance display authenticity among employees. We also offer some implications regarding the optimal allocation of resources to increase employee display authenticity and managing customer inferences of deception.

In the next section, we establish our conceptual background pertaining to display authenticity, EASI theory, and regulatory focus theory, on the basis of which we develop our hypotheses. Following recent calls to investigate service interactions between customers and employees as the unit of analysis (Groth et al. 2019), we test our hypotheses with a dyadic field study and provide further evidence in three experiments in which we manipulate authenticity and regulatory focus. Finally, we discuss the theoretical and practical implications of our findings to conclude.

\section{Conceptual Background and Hypotheses}

\section{Display Authenticity and the EASI Model}

In service industries, FLEs often must display positive emotions to achieve the required service delivery, whether that display is authentic or inauthentic (Paul, Hennig-Thurau, and Groth 2015). Positive displays are authentic if FLEs' experienced and expressed emotions are aligned (Hennig-Thurau et al. 2006). FLEs might express naturally occurring positive emotions (Diefendorff, Croyle, and Gosserand 2005) or use deep acting, a strategy that produces genuine positive emotions (Grandey 2003), such as by visualizing a past event that made them feel good (Gross 1998). Emotion displays produced with deep acting do not differ from naturally occurring positive emotion displays in their authenticity (Hülsheger and Schewe 2011). When experienced and expressed emotions are not aligned, the emotion display is inauthentic (i.e., surface acting; Hennig-Thurau et al. 2006). Substantial literature outlines the effects of display authenticity for FLEs (Hülsheger and Schewe 2011; Mesmer-Magnus, DeChurch, and Wax 2012); we instead seek to clarify customer reactions to authentic emotion displays (Grandey and Gabriel 2015) by drawing on EASI theory (van Kleef 2009).

According to EASI theory (van Kleef 2014), expressed emotions by FLEs provide information about the affective experience of the employee and her or his inferred intention toward 
the customer (Keltner and Haidt 1999), which influences customers through cognitive and affective processes (van Kleef 2009). By extending the EASI model to the authenticity of positive emotion displays (Wang et al. 2017), we posit that authentic displays might result in more positive customer reactions than inauthentic ones (Hennig-Thurau et al. 2006), though few studies have empirically investigated customers' reactions to authenticity (Groth, Hennig-Thurau, and Walsh 2009; Hennig-Thurau et al. 2006). Still, this research domain indicates considerable heterogeneity in these effects (MesmerMagnus, DeChurch, and Wax 2012; Wang, Seibert, and Boles 2011), and social interaction models (e.g., EASI) suggest this heterogeneity might be explained by individual differences in customers' motivation (van Kleef 2014). We introduce regulatory focus (Higgins 1998) as a key motivational construct that shapes customers' inferences about display (in)authenticity.

\section{Regulatory Focus Theory}

Customers might pursue goals by adopting distinct motivations: prevention or promotion (Higgins 1998, 2012). A prevention focus implies a concern for safety and security (Higgins 2012; Higgins and Cornwell 2016), so customers with a strong prevention focus are vigilant (Higgins 2012; Higgins and Cornwell 2016). In social contexts, they screen the environment for cues that might indicate insufficient security in interactions (Winterheld and Simpson 2011) such as inauthentic emotion displays. A promotion focus instead implies a concern for growth, and customers with a strong promotion focus tend to be eager (Higgins 2012; Higgins and Cornwell 2016). In social interactions, they are less likely to screen their environment for security cues (Winterheld and Simpson 2011) and thus might be less concerned with inauthentic emotion displays.

Although customers have chronic tendencies to embrace a promotion or prevention state, these motivations also can operate as temporary psychological states, activated by situational demands (Pham and Avnet 2004). For example, a task that demands vigilance may momentarily override customers' chronic promotion tendencies and place them in a temporary prevention state, or vice versa. Therefore, when extending regulatory focus theory to new phenomena (e.g., display authenticity), it is pertinent to consider both chronic individual differences and temporary states, especially because past research indicates that temporary states may have stronger effects on evaluations and intentions than chronic individual differences (Motyka et al. 2014).

Prevention and promotion orientations affect emotions on the intrapersonal level; for example, promotion-focused customers are more likely to experience cheerfulness and dejection, but prevention-focused customers are prone to experience quiescence and agitation (Brockner and Higgins 2001; Higgins and Cornwell 2016; Higgins, Shah, and Friedman 1997; Yen, Chao, and Lin 2011). We know less about how regulatory focus shapes consumers' reactions to others' emotions (for an isolated experiment on the effects of angry vs. happy instructors on prevention- vs. promotion-focused students' learning see van Doorn, van Kleef, and van der Pligt 2014). Advancing regulatory focus theory in service literature demands such considerations though because of the social nature of services and emerging evidence about the social functions of emotions (van Kleef 2014). Integrating regulatory focus theory with EASI, we predict that consumers' prevention or promotion focus shapes their inferences of social information, including display authenticity.

\section{Research Hypotheses}

We expect distinct customer reactions to inauthentic but not authentic displays. Specifically, we predict decreased service performance for preventers compared with promoters who encounter inauthentic emotion displays. In line with extant studies (Huang and Dai 2010; Hülsheger et al. 2015), we conceptualize service performance as customer-based FLE output, which can be measured with objective performance indicators such as tips or subjective performance indicators such as customer satisfaction.

Drawing on the EASI model (van Kleef 2009), we propose that the effect of inauthentic displays on service performance is driven by inferential processes. This rationale builds on the interpretational ambiguity of inauthentic emotion displays (Lavan et al. 2015; Sporer and Schwandt 2007), which might not be construed by all customers as manipulative but rather might depend on the customers' regulatory focus. Preventionfocused customers' more dedicated attention to manipulative information may cause them to infer deception when they encounter inauthentic emotion displays, so these preventers likely identify that employees are hiding their true emotions, leading them to regard the inauthentic displays as deceptive. Promotionfocused customers instead should be less likely to construe inauthentic displays as deceptive because their prioritization of growth over safety prompts them to interpret inauthentic emotion displays benevolently, noting that the employee smiles, even while not experiencing positive emotions. This reasoning is echoed by Kirmani and Zhu (2007, Study 1), who experimentally induce a prevention or a promotion focus and measure customers' attitudes toward potentially manipulative advertisements (i.e., high in ambiguity). They find that brand attitudes decrease more among preventers than among promoters.

Although we expect different customer reactions to inauthentic displays among preventers versus promoters, we do not expect differences if the emotion displays are authentic because such displays exceed most customers' expectations (Chi et al. 2011) and allow both preventers and promoters to fulfill their consumption goals. Specifically, authentic displays are not perceived as manipulative (Grandey et al. 2005), so prevention-focused customers can meet their consumption goal. An authentic smile also creates a positive experience (Hennig-Thurau et al. 2006), so promotionfocused customers can meet their consumption goals too. Because customers' needs are fulfilled, additional increases in service performance due to their regulatory focus are unlikely. Formally, we propose: 
Hypothesis 1: Inauthentic (cf. authentic) employee emotion displays decrease service performance more for preventionfocused than for promotion-focused customers.

To delineate how inauthentic displays differently affect service performance for prevention- and promotion-focused customers, we build on the EASI model, which predicts that emotional expressions in general affect customers' affective reactions and cognitive inferences (such as perceived deception; van Kleef, de Dreu, and Manstead 2010). Convergent research shows that the effects of authenticity tend to be driven by cognitive inferences (e.g., Groth, Hennig-Thurau, and Walsh 2009; Wang et al. 2017), and inferred deception is a key cognitive inference in this context (Grandey et al. 2005), so we include it as a potential mediating factor in the direct test of our theoretical rationale. Deception is an inference that a counterpart is presenting misinformation (Au and Wong 2019; Bond et al. 1992); we propose that it captures differential interpretations of display authenticity by prevention- versus promotion-focused customers.

Specifically, we expect preventers to interpret inauthentic displays as deceptive because they focus on manipulative information (Kirmani and Zhu 2007). For promoters, we do not expect such an effect of inauthentic displays on inferred deception, due to their prioritization of growth over safety, which should result in benevolent interpretations of inauthentic displays. Research in psychology supports this notion, by showing that preventers but not promoters screen their social environments for cues, including inauthentic displays that could signal low security in interactions (Winterheld and Simpson 2011). In that case, deception inferences should provide a critical predictor of service performance, such that it decreases when customers interpret FLEs' emotion displays as deceptive. This reasoning also builds on the intangibility of services, which makes the social interaction between FLEs and customers more critical (Zeithaml, Bitner, and Gremler 2013) and thus increases the salience of deception for service performance judgments. Various studies similarly note the negative effects of deceptive advertising on brand attitudes (Kirmani and Zhu 2007), of employee lies on corporate perceptions (Jehn and Scott 2008), and of inferred deception on customer satisfaction in online retailing settings (Riquelme, Román, and Iacobucci 2016). Therefore, we propose that the negative effect of inauthentic displays on service performance for preventionfocused (but not promotion-focused) customers results from their inferences of deception (see Figure 1), such that:

Hypothesis 2: The conditional effect of employee emotion display authenticity on service performance is mediated by inferred deception.

\section{Alternative Affective Account}

The EASI model also includes affective reactions, which might explain how emotional expressions affect customers (van Kleef 2014). We rely on convergent evidence that indicates cognitive inferences represent central drivers of authenticity effects

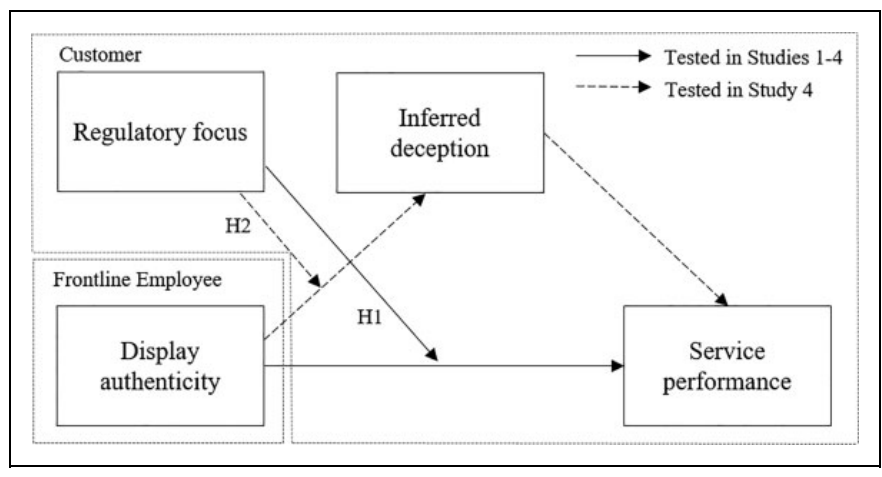

Figure I. Conceptual framework.

Note. We controlled for customer gender, customer age, café busyness, group size, and patronage frequency in Study I; customer gender in Studies 2 and 3; and gender and positive affect in Study 4. The significance levels and direction of effects remain unaffected by the inclusion of any of the control variables.

(Grandey et al. 2005; Groth, Hennig-Thurau, and Walsh 2009; Wang et al. 2017), yet we also acknowledge findings offered by Hennig-Thurau et al. (2006). They randomly assigned participants to interact with authentically (vs. inauthentically) smiling employees in a store setting and uncovered increased positive affect following the service encounter, suggesting the possibility of an affective pathway from the EASI model as relevant to studies of authenticity (van Kleef 2009).

Overall then, we prioritize preventers' natural inclination to screen social environments for potentially deceptive cues as an explanation (Higgins et al. 2001; Winterheld and Simpson 2011). Because regulatory focus literature is silent on the role of affective reactions to social environments, and we cannot conclusively exclude an alternative account based on affect, we aim to isolate the predicted deception-based mechanism by testing the role of affect empirically, as a competitive potential mediator.

\section{Overview of Studies}

Across four studies, we test whether customer regulatory focus interacts with FLE display authenticity in predicting service performance (Hypothesis 1). In Study 1, a dyadic field study with two independent information sources (customers and employees), we establish this effect using an objective performance indicator (tips). In Study 2, we adopt an experimental approach to manipulate authenticity and conceptually replicate the results of Study 1. Both Studies 1 and 2 rely on established measures of a chronic regulatory focus; we instead prime prevention in Studies 3 and 4, using different methods, to draw stronger causal inferences. Study 4 also sheds light on the underlying psychological process, by testing the predicted mediated moderation through inferred deception (Hypothesis 2).

\section{Study I: Field Study}

To establish that regulatory focus moderates the effect of display authenticity on service performance (Hypothesis 1), we 
conducted a dyadic field study. This design reflects recent calls to "examine service episodes between employees and customers as the unit of analysis" (Groth et al. 2019, p. 106). We featured tipping as a consequential dependent variable and an objective indicator of service performance (Hülsheger et al. 2015), which denotes customers' voluntarily reward for employees' performance, beyond the contracted service price (Lynn, Zinkhan, and Harris 1993).

\section{Method}

We cooperated with a local, medium-sized café in a large city in southern Germany to survey employee-customer dyads following service delivery incidents. Employees invited customers to participate in a short survey, and if they agreed, customers completed it in the absence of the employee. Simultaneously, employees completed a short survey. The customers and employees then placed the sealed surveys in a secured box at the exit of the café, accessible only to the lead researcher. This common approach to dyadic research helps ensure honest responses from both sides (e.g., Chi et al. 2011). All customer and employee surveys contained matched codes so that we could identify employee-customer dyads. We ultimately obtained 118 dyadic surveys, which represented input from about nine full-time employees $(M=13.11, S D=3.48)$. These employees averaged 43.00 years of age $(S D=8.50)$, and $89 \%$ of them were women. Customers averaged 52.09 years $(S D=$ $16.64)$, and $65.30 \%$ were women.

The customer survey included measures of tipping, regulatory focus, and demographics. We asked customers about the bill total and tip amount, which we converted to a percentage for the analysis, by dividing the tip by the bill total $(M=.13$, $S D=.08$; Chi et al. 2011). To reduce interference with the natural service setting (Matthews and Gibbons 2016), we measured prevention and promotion focus separately, with an established 7-point summary item (prevention, "In general, I am focused on preventing negative events in my life"; $M=$ $5.23, S D=1.96$; promotion, "In general, I am focused on achieving positive outcomes in my life"; $M=6.22, S D=$ 1.17; Lockwood, Jordan, and Kunda 2002). Following established conventions in tipping research (e.g., Chi et al. 2011), we also measured the busyness of the cafe $(M=2.95, S D=.92)$, group size $(M=2.41, S D=1.11)$, and patronage frequency $(M=29.01, S D=67.98)$ as control variables. The employee survey included a 1-item, 7-point measure of displayed authenticity during the interaction, adapted from Yagil (2014; "The emotions I expressed to these customers were genuine"; $M=$ $5.49, S D=1.12)$. The procedure and all the measures are listed in the Appendix.

\section{Results}

Employees completed several dyadic surveys, so we accounted for the nested data structure in our analysis by using a recommended fixed effects approach with dummy-coded grouping variables (Huang 2016). This approach is especially feasible for our analysis because the group number (i.e., employees) in our sample is rather low (9), and our research question focuses on Level 1 relationships (i.e., customer-employee dyad; Huang 2018). The intraclass correlation coefficient (ICC(1)) of our dependent variable was .06, and the design effect was 1.87 .

To test Hypothesis 1, we computed a predominance measure of regulatory focus by subtracting the promotion scores from the prevention scores (Das, Mukherjee, and Smith 2018; Sengupta and Zhou 2007), which indicates the relative strength of a prevention over a promotion focus (Lockwood, Jordan, and Kunda 2002). We regressed tip percentage on authenticity, prevention predominance, their interaction, and the dummycoded grouping variables $\left(R^{2}=.17\right)$. All scales were mean centered before the analyses, which in turn revealed no significant main effects of authenticity $(\beta=.00, S E=.01, n s)$ or prevention predominance $(\beta=-.00, S E=.00, n s)$. As we predicted though, the interaction of authenticity and prevention predominance was significant $\left(\beta=.01, S E=.00, p<.05 ; \Delta R^{2}\right.$ $=.05)$, in support of Hypothesis 1 . According to the floodlight analyses, prevention-focused customers tipped less when employee displays were more inauthentic (Johnson-Neyman [JN] value $1_{\text {authenticity }}=4.43 ; \beta=-.013, S E=.007$, $t=1.98, p=.05)$, compared with more authentic (JN value $2_{\text {authenticity }}=6.84 ; \beta=.013, S E=.007, t=1.98$, $p=.05)$. Display authenticity exerted an effect on tipping only among prevention predominant customers $\left(\mathrm{JN}\right.$ value $_{\text {prevention predominance }}=.81 ; \beta=.023, S E=.012$, $t=1.98, p=.05)$. The interaction remained significant even when we included group size, café busyness, patronage frequency, customer gender, and customer age as control variables; they were all insignificant.

To test the robustness of our results, we reran the analysis using a random intercept two-level model, controlling for the effects of employees at Level 2 (Chi et al. 2011). This approach was shown to yield unbiased Level 1 estimates even when sample size at Level 2 is low (Maas and Hox 2004). We group-mean centered all predictors, which "removes all between-cluster variation from the predictor and yields a 'pure' estimate of the pooled within-cluster (i.e., Level 1) regression coefficient" (Enders and Tofighi 2007, p. 128). Similar to the fixed effects analysis, we obtained no significant main effects of display authenticity $(\beta=.07 ; S E=.08, n s)$ and prevention predominance $(\beta=.02 ; S E=.12, n s)$ but found a significant interaction of display authenticity and prevention predominance $(\beta=.13 ; S E=.06, p<.05) .{ }^{1}$ Study 1 thus presented evidence that prevention-focused customers tip less than promotion-focused customers when FLEs display inauthentic (cf. authentic) emotions.

\section{Study 2: Experimental Manipulation of Employee Authenticity}

To confirm the findings of our nonexperimental, dyadic field study, we needed to conduct an experimental manipulation of authenticity in a controlled setting, to support stronger causal inferences about the proposed conditional effect of 
authenticity. In addition, to extend the generalizability of our findings, we sought to replicate Study 1 with an established, multi-item regulatory focus measurement scale.

\section{Method}

This randomized experiment relied on two short films to manipulate authenticity (Lechner and Paul 2019). The sample consisted of 190 participants from a large customer panel in Germany, with a mean age of 38.88 years $(S D=10.53)$, of whom $53.20 \%$ were women. The cell sizes ranged from 92 to 98 participants. They first completed a standard regulatory focus scale (Higgins et al. 2001). We measured both regulatory foci as stable dispositions, using established measures from Higgins et al. (2001; prevention 5 items; promotion 6 items).

Next, a vignette experiment manipulated authenticity by asking all participants to imagine going out to dinner. They watched a short film depicting a restaurant visit from customers' point of view, starting with the server approaching the table, handing over the menu, and taking the order. In the video, an experienced actor trained in emotional labor techniques performed a scripted restaurant interaction in a mid-priced restaurant. The actor used either deep acting techniques in the high authenticity condition or surface acting techniques in the low authenticity condition. Other than these differences in the authenticity of the emotion display, the remaining facets of the emotional expression were identical in both films (e.g., teeth visible in all smiles). Both films were approximately 40 seconds long (see Appendix). Thereafter, participants completed a satisfaction scale, as our measure of service performance, using an established 3-item scale (Burnham, Frels, and Mahajan 2003; Keh et al. 2013). We considered customer satisfaction, which reflects the customer's fulfillment response according to a comparison of expectations and service outcomes (Oliver 2010), to enhance the generalizability of our results (Huang and Dai 2010).

The descriptive statistics and reliability estimates of our model variables are in Table 1. A confirmatory factor analysis of the validity of all constructs revealed acceptable fit of the model, $\chi^{2}(70)=114.15, p<.05$; comparative fit index $(\mathrm{CFI})=$ .96; Tucker-Lewis Index (TLI) $=.94$; root-mean-square error of approximation (RMSEA) $=.06$; standardized root mean squared residual $($ SRMR $)=.07$. However, it did not support the convergent validity of prevention and promotion focus (average variance extracted $(\mathrm{AVE})<.5$ ). In an iterative process, we removed 1 prevention and 2 promotion items to improve AVEs. ${ }^{2}$ The reestimated model $\chi^{2}(40)=41.89, n s$; $\mathrm{CFI}=.99 ; \mathrm{TLI}=.99 ; \mathrm{RMSEA}=.02 ; \mathrm{SRMR}=.04$ achieved convergent validity for prevention (.51) and satisfaction (.93; AVE > .5). Although the AVE for promotion (.37) was still below .5 , its composite reliability after item removal (.7) met the required threshold (Hulland 1999). Also, Fornell and Larcker (1981, p. 46) stated that "on the basis of $\rho c$ alone [composite reliability], the researcher may conclude that the convergent validity of the construct is adequate, even though more than $50 \%$ of the variance is due to error." We found
Table I. Descriptive Statistics, Reliabilities, and Correlations.

\begin{tabular}{|c|c|c|c|c|c|}
\hline \multirow[b]{2}{*}{ Variable } & \multirow[b]{2}{*}{ M } & \multirow[b]{2}{*}{$S D$} & \multirow{2}{*}{$\begin{array}{c}\text { Cronbach's } \\
\alpha\end{array}$} & \multicolumn{2}{|c|}{ Correlations } \\
\hline & & & & $\mathrm{I}$. & 2. \\
\hline \multicolumn{6}{|l|}{ Study I } \\
\hline I. Tip percentage & 0.13 & 0.08 & - & & \\
\hline 2. Display authenticity & 5.49 & 1.12 & - & .01 & \\
\hline $\begin{array}{l}\text { 3. Prevention } \\
\text { predominance }\end{array}$ & -0.99 & 1.82 & - & .04 & -.12 \\
\hline \multicolumn{6}{|l|}{ Study 2} \\
\hline $\begin{array}{l}\text { I. Customer } \\
\text { satisfaction }\end{array}$ & 6.34 & 0.78 & .92 & & \\
\hline $\begin{array}{l}\text { 2. Prevention } \\
\text { predominance }\end{array}$ & -0.63 & 1.59 & - & -.13 & \\
\hline \multicolumn{6}{|l|}{ Study 3} \\
\hline $\begin{array}{l}\text { I. Customer } \\
\text { satisfaction }\end{array}$ & 6.38 & 1.02 & .96 & & \\
\hline \multicolumn{6}{|l|}{ Study 4} \\
\hline $\begin{array}{l}\text { I. Customer } \\
\text { satisfaction }\end{array}$ & 5.10 & 1.42 & .91 & & \\
\hline 2. Inferred deception & 2.68 & 1.53 & .97 & -.67 & \\
\hline 3. Positive affect (post) & 4.02 & 1.35 & .89 & .54 & -.40 \\
\hline
\end{tabular}

support for discriminant validity; all AVEs were greater than all squared correlations (Fornell and Larcker 1981). As in Study 1 , we computed the prevention predominance score by subtracting promotion scores from prevention scores (Das, Mukherjee, and Smith 2018; Sengupta and Zhou 2007). To confirm the effectiveness of the authenticity manipulation, we adapted 2 items from Côté, Hideg, and van Kleef (2013). The split-half reliability was .82. Finally, we gathered demographic measures and debriefed the participants.

\section{Pretest and Manipulation Checks}

A pretest $(n=64)$ confirmed that participants in the high (vs. low) authenticity condition reported significantly higher authenticity (split-half reliability $=.93 ; M_{\text {high authenticity }}=$ $\left.5.17 ; M_{\text {low authenticity }}=3.60 ; t(62)=3.80, p<.05\right)$. In the main study, we confirmed the success of the authenticity manipulation with the same items. Participants again reported higher authenticity in the high authenticity condition $\left(M_{\text {high authenticity }}\right.$ $\left.=4.79 ; M_{\text {low authenticity }}=4.18 ; t(188)=2.76, p<.05\right)$.

\section{Results}

To test Hypothesis 1, we regressed satisfaction on authenticity, prevention predominance, and their interaction $\left(R^{2}=.09\right)$. To ensure a substantive interpretation of the main effects, we effect coded the authenticity manipulation and mean centered the prevention predominance scale before the analysis (Hayes 2013). This analysis revealed a significant main effect of authenticity $\left(M_{\text {high authenticity }}=6.48 ; M_{\text {low authenticity }}=6.19\right.$; $\beta=.15, S E=.06, p<.05)$ but no main effect of prevention predominance $(\beta=-.05, S E=.04, n s)$. In support of Hypothesis 1 , the interaction of authenticity and prevention 
predominance was significant $(\beta=.09, S E=.04, p<.05$; $\Delta R^{2}=.03$ ). According to the floodlight analysis, display authenticity affected satisfaction only among prevention predominant customers ( $\mathrm{JN}$ value $\mathrm{e}_{\text {prevention predominance }}=-1.66$; $\beta=.112, S E=.057, t=1.97, p=.05)$, such that they were significantly less satisfied in response to inauthentic displays $(\beta=-.14, S E=.05, p<.05)$. We found no effect of this prevention predominance for authentic displays $(\beta=.04$, $S E=.05, n s)$. The results also remained unchanged when we included customer gender $(1=$ female,$-1=$ male $)$ as a control variable $(\beta=17, S E=.05, p<.05)$. A nonhypothesized interaction among authenticity, prevention predominance, and customer gender also was not significant. ${ }^{3}$

Study 2 thus provided further support for Hypothesis 1. As in Study 1, preventers (cf. promoters) reacted negatively to inauthentic displays by FLEs, whereas their reactions to authentic displays did not appear moderated by their regulatory focus.

\section{Study 3: Regulatory Focus Primes}

In Studies 1 and 2, when we operationalized regulatory focus as a chronic disposition, service performance decreased for customers with a prevention (not promotion) regulatory focus if FLEs' emotional displays were inauthentic. To draw stronger causal inferences, we manipulated regulatory focus in Study 3 and thereby investigated whether decreases in service performance associated with inauthentic displays were conditional on prevention (but not promotion) even if regulatory focus was primed rather than measured.

\section{Method}

This 2 (authenticity: high vs. low) $\times 2$ (regulatory focus prime: prevention vs. promotion) randomized between-subjects experiment used a series of pictures to manipulate authenticity (Lechner and Paul 2019). The sample consisted of 106 participants in a large UK customer panel, with a mean age of 32.92 years $(S D=9.45), 55.70 \%$ of whom were women.

We applied an established regulatory focus priming procedure (Beersma et al. 2013; Higgins et al. 1994). In the prevention focus prime condition, participants wrote down two past and two present duties and obligations. In the promotion condition, they wrote down two past and two present hopes and goals (Freitas and Higgins 2002; Gamez-Djokic and Molden 2016; Pham and Avnet 2004). Next, a vignette experiment manipulated authenticity, such that all participants had to imagine they had a job interview early the next morning in a distant city and that they were checking into a hotel for an overnight stay. A series of pictures depicted a hotel check-in scene, from customers' point of view, including a FLE greeting the customer, checking the reservation, and handing over a room key. A trained actor, different from the one used in Study 2, leveraged emotional labor techniques to regulate emotion displays during the photo shoot in a local hotel (see Appendix). The smile intensity of authentic and inauthentic displays remained constant, but in the low display authenticity condition, the actor displayed an asymmetric smile, another common way to express a lack of felt positive emotions (Skinner and Mullen 1991). In the high authenticity condition, the actor displayed a natural, symmetric smile. Apart from these differences, the emotional expressions were identical across series. Finally, the participants completed a survey that included the satisfaction measure from Study $2(M=6.38, S D=1.02 ; \alpha=.96)$, as well as the authenticity manipulation check (split-half reliability = .87), demographic items, and the debriefing, as in Study 2.

\section{Pretest and Manipulation Checks}

The pretest $(n=60)$ confirmed that participants in the high (vs. low) authenticity condition reported significantly higher authenticity (split-half reliability $=.94 ; M_{\text {high authenticity }}=5.40 ; M_{\text {low }}$ authenticity $=3.23 ; t(58)=5.81, p<.05)$, but identified no significant differences in smile intensity $\left(M_{\text {high authenticity }}=3.47\right.$; $\left.M_{\text {low authenticity }}=3.30 ; t(58)=0.40, n s\right)$. This pretest also confirmed the effectiveness of the regulatory focus prime, using items from Pham and Avnet (2004; split-half reliability = .95). Participants in the prevention condition reported significantly higher prevention scores than those in the promotion condition $\left(M_{\text {prevention }}=4.97 ; M_{\text {promotion }}=4.03 ; t(58)=2.23\right.$, $p<.05$ ). Both manipulations were unconfounded with the other (all $p$ s > .05; Perdue and Summers 1986).

In the main study, the participants again reported higher authenticity in the high (vs. low) authenticity condition, $M_{\text {high authenticity }}=5.18 ; M_{\text {low authenticity }}=3.80 ; t(95)=4.92, p$ $<.05$. To test the effectiveness of the regulatory focus prime in the main study, two independent coders, blind to the participants' experimental condition and our hypotheses, coded all four statements from participants as indicating a prevention, promotion, or neither regulatory focus (proportional reduction in loss $(P R L)=.95$, Rust and Cooil 1994). A third coder resolved any disagreements. This coding identified nine cases that we deemed invalid. Therefore, the analysis included 97 cases with valid induction. The cell sizes ranged from 21 to 28 entries.

\section{Results}

A two-way analysis of variance with authenticity, regulatory focus, and their interaction as means to explain satisfaction $\left(\eta_{\mathrm{p}}^{2}=.10\right)$ revealed a significant main effect of authenticity $\left(M_{\text {high authenticity }}=6.60 ; M_{\text {low authenticity }}=6.15 ; F(1,93)=4.66\right.$, $p<.05)$, but not regulatory focus $\left(M_{\text {promotion }}=6.44 ; M_{\text {prevention }}\right.$ $=6.32 ; F(1,93)=0.57, n s)$. In support of Hypothesis 1 , the main effect of authenticity was qualified by a significant, twoway interaction of authenticity and regulatory focus $(F(1,93)$ $\left.=4.36, p<.05 ; \eta_{\mathrm{p}}^{2}=.05\right)$. As Figure 2 shows, satisfaction was significantly lower in the prevention (vs. promotion) group when displays were inauthentic $\left(M_{\text {Low Authenticity }} \times\right.$ Prevention $=$ 5.86; $M_{\text {Low Authenticity } \times \text { Promotion }}=6.43 ; F(1,93)=9.71$, $p<.05)$. However, no such difference arose when displays were authentic $\left(M_{\mathrm{High}}\right.$ Authenticity $\times$ Prevention $=6.71$; $\left.M_{\text {High Authenticity } \times \text { Promotion }}=6.44 ; F(1,93)=.00, n s\right)$. The 


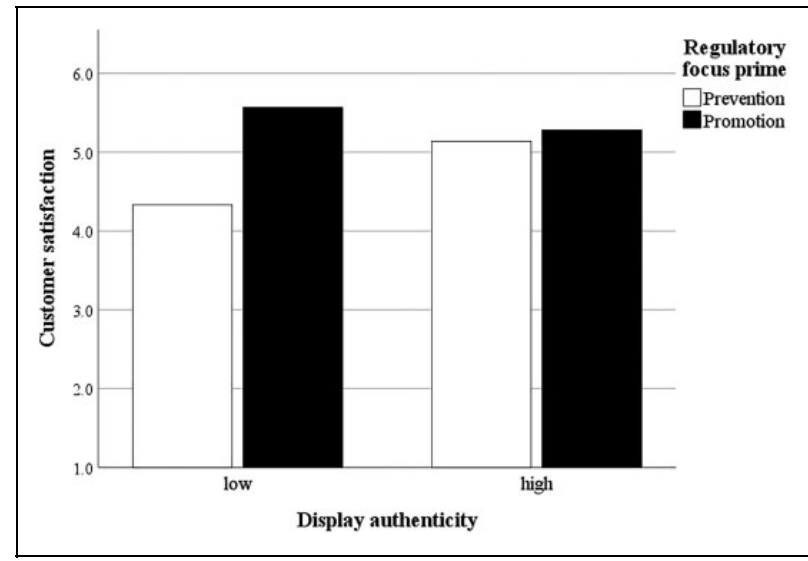

Figure 2. Satisfaction as a function of regulatory focus and authenticity, Study 3.

results remained unchanged when we introduced customer gender, which was insignificant, as a control variable.

Thus in Study 3, we again found support for Hypothesis 1. Inauthentic FLE displays negatively affected service performance only if participants had been primed to adopt a prevention (rather than promotion) focus.

\section{Study 4: Managerial Regulatory Focus Primes and Inferred Deception}

With Study 3, we demonstrated that decreases in service performance associated with inauthentic displays were conditional on prevention (but not promotion) when regulatory focus was primed rather than measured. With Study 4, we replicated these findings with a managerially relevant regulatory focus prime (product descriptions) and explored psychological mechanisms that might explain the conditional effect of display authenticity on service performance. We expected that prevention-primed, but not promotion-primed, participants would infer deception from inauthentic displays (Hypothesis 2). Furthermore, we tested our cognitive account relative to an affective account proposed by EASI theory as an alternative mechanism (van Kleef 2009).

\section{Method}

We conducted a 2 (authenticity: high vs. low) $\times 2$ (regulatory focus prime: prevention vs. promotion) randomized, betweensubjects, online experiment. The sample comprised 144 participants from a large UK customer panel with a mean age of 36.00 years $(S D=10.74) ; 64.60 \%$ of them were women. The cell sizes ranged from 33 to 39 respondents.

The vignette experiment manipulated FLE display authenticity and customer regulatory focus. That is, all participants had to imagine they were going out to dinner that night, and they reviewed a series of pictures of a server who introduced herself and informed customers about a new grape juice added to the restaurant's drink assortment. To manipulate authenticity, we used six pictures taken from the video stimuli used in Study 2. Each picture was accompanied by a speech balloon, containing greetings and descriptions of the grape juice. We manipulated regulatory focus by adapting the product description (Lee and Aaker 2004). Specifically, the server elaborated on the health and disease-prevention benefits of the juice in the prevention condition (e.g., "purple grape juice may contribute to healthy cardiovascular function") but the energy benefits and pleasurable taste in the promotion condition (e.g., "purple grape juice may contribute to the creation of greater energy"). Next, participants completed the satisfaction measure from our previous studies. We also measured deception inferences with 4 items from Darke and Ritchie (2007) and positive affect after the service encounter with 4 items from Hennig-Thurau et al. (2006). The descriptive statistics and reliability estimates for our model variables are in Table 1 . The confirmatory factor analysis with all constructs from our model and positive affect $\left(\chi^{2}(37)=76.71, p<.05 ; \mathrm{CFI}=.98 ; \mathrm{TLI}=.97 ; \mathrm{RMSEA}=.09\right.$; SRMR $=.04)$, indicated support for the convergent validity of satisfaction (.78), inferred deception (.81), and positive affect (.65; all AVEs $>.5$ ) and for discriminant validity because the AVEs were greater than all squared correlations (largest $r^{2}=$ 45; Fornell and Larcker 1981).

We used 2 items from Lee and Aaker (2004) for the regulatory focus manipulation check ("The juice helps keeping arteries unclogged"; "The juice is healthy to drink"; split-half reliability $=.62$ ), which were not aggregated due to their low reliability. The authenticity manipulation check (splithalf reliability $=.87$ ), demographic items, and debriefing were identical to those in Study 2.

\section{Pretest and Manipulation Checks}

The pretest $(n=62)$ confirmed that participants in the high (vs. low) authenticity condition reported significantly higher authenticity scores (split-half reliability $=.93 ; M_{\text {high authenticity }}$ $\left.=4.87 ; M_{\text {low authenticity }}=2.98 ; t(60)=5.80, p<.05\right)$. Participants in the prevention (vs. promotion) condition reported significantly higher prevention scores (healthy, $M_{\text {prevention }}=6.29$; $M_{\text {promotion }}=5.61 ; t(58)=2.13, p<.05 ;$ arteries unclogged, $\left.M_{\text {prevention }}=6.12 ; M_{\text {promotion }}=2.43 ; t(58)=10.80, p<.05\right)$. The manipulations were unconfounded (all $p>.05$ ).

The main study results reconfirmed the higher authenticity scores in the high (vs. low) authenticity condition $\left(M_{\text {high authenticity }}=4.78 ; M_{\text {low authenticity }}=4.19 ; t(142)=\right.$ $1.99, p<.05)$ and higher prevention scores in the prevention (vs. promotion) condition (healthy, $M_{\text {prevention }}=6.32$; $M_{\text {promotion }}=5.56 ; t(142)=2.22, p<.05 ;$ arteries unclogged, $M_{\text {prevention }}=5.99 ; M_{\text {promotion }}=3.25 ; t(142)=$ $10.64, p<.05)$. The manipulations again were unconfounded with each other (all $p>.05$ ).

\section{Results}

We tested our hypotheses using a two-way analysis of variance including authenticity, regulatory focus, and their interaction $\left(\eta_{\mathrm{p}}^{2}=.10\right)$ and found a significant main effect of regulatory focus $\left(M_{\text {promotion }}=5.42 ; M_{\text {prevention }}=4.78 ; F(1,140)=9.13\right.$, 


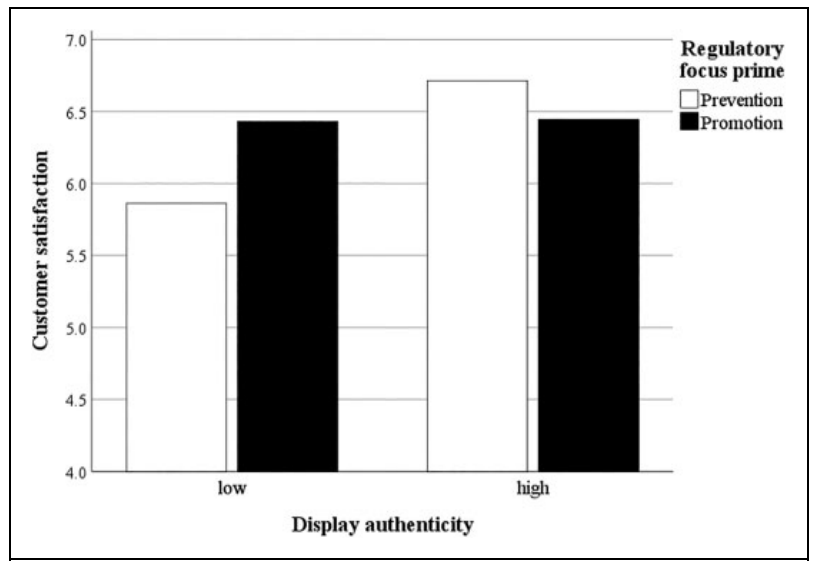

Figure 3. Satisfaction as a function of regulatory focus and authenticity, Study 4.

$p<.05)$, but not authenticity $\left(M_{\text {high authenticity }}=5.21\right.$; $\left.M_{\text {low authenticity }}=4.96 ; F(1,140)=1.30, n s\right)$. Again in support of Hypothesis 1, the two-way interaction effect of authenticity and regulatory focus was significant $(F(1,140)=5.76, p<.05$; $\left.\eta_{\mathrm{p}}^{2}=.04\right)$. As we show in Figure 3, satisfaction was significantly lower in the prevention (vs. promotion) condition when displays were inauthentic $\left(M_{\text {Low Authenticity } \times \text { Prevention }}=4.33\right.$; $\left.M_{\text {Low Authenticity } \times \text { Promotion }}=5.57 ; F(1,140)=13.74, p<.05\right)$, but we found no difference when the displays were authentic $\left(M_{\text {High Authenticity }} \times\right.$ Prevention $=5.14 ; M_{\text {High Authenticity } \times \text { Promotion }}$ $=5.28 ; F(1,140)=.21, n s)$.

To test our mediated moderation hypothesis (Hypothesis 2), we used bootstrapping in the Process macro for SPSS 26 (Model 8; 10,000 samples; Hayes 2013). Table 2 shows the results. In line with Hypothesis 2, we found a significant interaction effect of authenticity and regulatory focus on inferred deception $\left(\beta=-.26, p<.05 ; \Delta R^{2}=.03\right.$; see Model 1 in Table 2). Specifically, prevention (vs. promotion) primes resulted in higher deception inferences for participants in the inauthentic display condition $(\beta=.51, S E=.18, p<.05)$, but no such difference occurred when displays were authentic ( $\beta=-.01, S E=.17, n s)$. As hypothesized, when we included inferred deception in Model 3, the interaction effect of authenticity and regulatory focus on satisfaction became insignificant $(\beta=.09, n s)$. In line with Hypothesis 2 , deception exerted a negative significant effect on satisfaction $(\beta=-.48, p<.05)$. The indirect effect of authenticity on satisfaction through inferred deception was not significant $(\beta=.08, S E=.07$, bootstrapped confidence interval $[\mathrm{CI}][-.05, .21])$. The conditional indirect effect was significant in the prevention focus condition $(\beta=.20, S E=.10$, bootstrapped CI $[.00, .41])$ but not in the promotion condition $(\beta=-.05, S E=.07$, bootstrapped CI $[-.19, .09]$; index of mediated moderation $=.25$, $S E=.12$, CI $[.01, .50])$, in support of the mediated moderation we predicted in Hypothesis 2.

When we tested positive affect as an alternative mediator in Model 2, the interaction of authenticity and regulatory focus on positive affect was insignificant $(\beta=.19, S E=.11, n s)$.
Positive affect imposed a significant effect on service performance $(\beta=.33, S E=.07, p<.05)$, but the index of mediated moderation was not significant (index $=.12, S E=.09, \mathrm{CI}$ $[-.02, .31])$, ruling out positive affect as an explanatory variable. These results remained unchanged when we introduced customer gender as a control variable, which was insignificant in all the analyses.

With Study 4, we thus again found support for Hypothesis 1. Inauthentic FLE displays negatively affected service performance only if participants had been subjected to a prevention prime. Moreover, we demonstrated that the interaction of authenticity and regulatory focus was mediated by inferred deception (Hypothesis 2), whereas we could rule out positive affect as a mediator.

\section{General Discussion}

Across four related studies, we consistently show that FLEs' display authenticity has a stronger effect on service performance when customers are concerned with safety and security (i.e., prevention focus). In Study 1, we follow recent calls to investigate service interactions between customers and employees as the unit of analysis (Groth et al. 2019) and demonstrate that customers with a predominant prevention focus tip FLEs who display inauthentic emotions less than they do FLEs who display authentic emotions. Customers with a predominant promotion focus do not exhibit this tendency. Study 2 replicates this moderating effect when we manipulate authenticity experimentally. In Studies 3 and 4, we adopt a temporary regulatory focus perspective and use different priming methods to replicate the moderating effect. In Study 4, we also confirm that the conditional effect of authenticity on service performance is mediated by deception, in that preventers but not promoters infer deception from inauthentic emotion displays.

With these findings, our study offers three major theoretical contributions. First, we address heterogeneous findings in prior literature regarding the effects of FLEs' display authenticity on customer behavior (Mesmer-Magnus, DeChurch, and Wax 2012; Wang, Seibert, and Boles 2011) by drawing on and testing a key component of EASI theory (van Kleef 2009), pertaining to customers' motivation to process the information provided in emotion displays. We introduce customers' prevention (vs. promotion) focus (Higgins 1998) as a key motivational construct and affirm that inauthentic displays affect service performance more negatively among customers with a predominant prevention (vs. promotion) focus. ${ }^{4}$ Thus, regulatory focus motivations account for some of the variance in customer reactions to display authenticity, which represents an important, heretofore untested implication of the EASI framework. Our findings complement and extend prior emotional labor literature, which has largely focused on the effects of employee-related factors (e.g., personality, race; Chi et al. 2011; Chi and Grandey 2019; Grandey, Houston, and Avery 2018) or customer-employee dyadic factors (e.g., service personalization, employee task performance; Chi and Chen 2019; 
Table 2. Results of Mediation Analysis, Study 4.

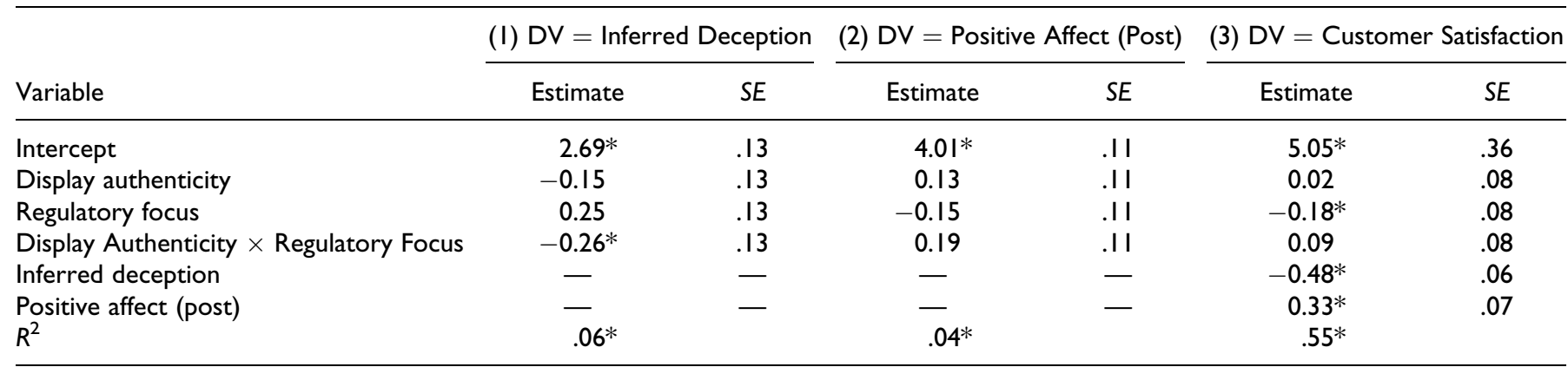

Note. Authenticity $(\mathrm{I}=$ high, $-\mathrm{I}=$ low $)$ and regulatory focus $(\mathrm{I}=$ prevention, $-\mathrm{I}=$ promotion $)$ were effect coded. $* p<.05$.

Grandey et al. 2005; Wang and Groth 2014), with limited insights for customer-related factors (Groth, Hennig-Thurau, and Walsh 2009; Houston, Grandey, and Sawyer 2018). More specifically, our findings extend seminal work by Groth, Hennig-Thurau, and Walsh (2009), who found that when customers detect (in)authenticity, it has a stronger effect. By considering regulatory focus, we offer insights on individual differences that shape attention to authenticity and manipulative information, which further confirms Groth, HennigThurau, and Walsh's (2009) work.

Second, we contribute to regulatory focus theory (Higgins 1998) by extending it to address interpersonal emotions. The predominant focus on the link between regulatory focus and emotions for intrapersonal effects (Brockner and Higgins 2001; Higgins and Cornwell 2016; Higgins, Klein, and Strauman 1985; Higgins, Shah, and Friedman 1997; Idson, Liberman, and Higgins 2000; Yen, Chao, and Lin 2011) has seemed endemic to regulatory focus theory, which defines prevention and promotion as self-regulatory motivations. Furthermore, a stagnation in more recent empirical work, as well as reviews, indicated that theory development in the domain of emotions and regulatory focus had reached maturity (Higgins and Cornwell 2016). However, the social functions of emotional displays highlight the importance of socially expressed emotions (Keltner and Haidt 1999; van Kleef 2014). By demonstrating that a prevention (vs. promotion) focus also shapes reactions to the inauthenticity of socially expressed emotion displays rather than just experiences of one's own emotions, our research encourages further theory development, achieved by integrating regulatory focus theory with the social functions of emotions. This shift in focus toward interpersonal emotions, for instance, directs attention toward different types of emotions that are more likely to be expressed and triggered socially such as love and envy (Laros and Steenkamp 2005) and raises questions about their relationship with regulatory focus.

Third, we detail the mechanism by which authentic emotion displays drive service performance for prevention-focused customers. In terms of EASI theory (van Kleef 2014), we confirm a cognitive but not affective path; inauthentic displays reduce service performance more for prevention-focused (vs. promotion-focused) customers because these preventers likely infer deception when confronted with inauthentic displays. This finding adds to authenticity literature by specifying which customers construe inauthentic displays as deceptive rather than assuming all of them do (Grandey et al. 2005; Gunnery and Hall 2014). Our finding also provides an interesting extension to Hennig-Thurau et al. (2006), who offered evidence for the affective mediation path. We suggest that even when affective reactions to authenticity are too weak to explain the conditional authenticity-service performance relationship, cognitive factors such as perceived deception may still elicit an effect. Importantly, in the context of our study, only preventionfocused customers infer deception from inauthentic displays.

\section{Implications for Managers}

This research offers solutions for firms confronting various circumstances. First, the priming studies suggest solutions when FLEs display inauthentic emotions. Situational demands may make the display of authentic emotions unlikely, such as in the presence of misbehaving customers (Sliter et al. 2010) or when employees are emotionally drained (Prati et al. 2009). Service firms also might hire workers who lack resources for emotion regulation, due to their dispositional characteristics (e.g., high in neuroticism; Liu et al. 2008). In these situations, managers can instruct employees to mitigate the negative effects of their inauthentic displays by priming a promotion focus among their customers. There are various ways to prime a promotion focus, such as by adjusting advertisements (Werth and Foerster 2007), slogans (Faddegon, Scheepers, and Ellemers 2008), or product descriptions (Lee and Aaker 2004). Employees also might communicate in a promotion-focused language (Gamache et al. 2013) or highlight specific promotion focus-related product benefits (as in Study 4).

Second, our finding that inauthentic emotion displays reduce service performance for prevention-focused customers because they interpret the displays as deceptive has implications for situations in which promotion primes are not feasible. To avoid negative service performance due to display inauthenticity, managers should communicate that the FLEs' inauthentic emotion displays are not actually an attempt at deception but instead stem from employee-related causes (e.g., drained resources). Another option would be to work to increase 
awareness about the negative effects of abusive treatment by customers, as exemplified by a recent marketing campaign by a large Australian service union (SDA Union 2018). When prevention-focused customers learn about underlying causes of FLE inauthenticity, they might be less inclined to interpret inauthentic expressions as attempts at deception, which should have net positive effects on service performance.

Third, this research offers implications regarding how to allocate resources to increase FLEs' display authenticity. A first step would be to determine customers' regulatory focus. Managers should collect data about their customers' regulatory focus, such as with surveys or derive it unobtrusively from customer-generated content (e.g., reviews; Gamache et al. 2013). Some services also are likely associated with a customer prevention focus inherently, such as preventive health care, 401(k) services (Zhou and Pham 2004) or restaurants that offer familiar and convenient foods (e.g., KFC in the United States; Pula, Parks, and Ross 2014). Multinational service firms might use national culture as a proxy, in that some countries exhibit a higher prevention focus than others (e.g., Japan vs. United States; Higgins, Pierro, and Kruglanski 2008). Using this information, managers can ensure that prevention-focused customers encounter authenticity; the revenues generated from superior service performance then might be used to fund training for FLEs who face mostly promotion-focused customers.

\section{Limitations and Further Research}

The evidence we present refers to different industries, representative of short- to medium-length interaction service encounters with positive display rules. It is unclear whether our findings also apply to longer interaction service encounters, such as soliciting a mortgage from a bank, and how these effects might play out in environments with display rules that are not restricted to positive emotions. To increase the generalizability of our results, continued research should investigate the moderating effect of regulatory focus in long service encounters and those in which employees might need to express negative emotions. We study face-to-face interactions, though some service providers deliver their offerings over the phone or other channels (e.g., medical consultation). Customers can detect authenticity in voice-to-voice interactions (Chi et al. 2011), which provides a rationale to extend our results to such encounters. Yet future research should investigate how regulatory focus functions in voice-to-voice encounters. A molar manipulation of authenticity (e.g., varying facial emotion expressions and vocal expressions), instead of the established molecular manipulation of authenticity (only varying facial expressions), also might be helpful. Field experiments or coding of employee emotion displays could extend the findings from our self-reported dyadic data too. Future research could also test whether the adoption of a display authenticity approach to emotional labor (EL) based on employee selfreports (Brach et al. 2015; Yagil 2014; Yagil and ShnapperCohen 2016) requires introspection and a reflection of the employees' intrapsychic experience; and whether mixing different theoretical approaches is problematic given that "[e]lements of all three approaches are, to varying degrees, represented in most theoretical treatments and empirical investigations of EL" (Grandey, Diefendorff, and Rupp 2013, p. 17). Furthermore, a test of the accuracy of employee self-reports of display authenticity (compared to self-reports of intrapsychic emotion regulation) can help define best research practices for dyadic research.

Finally, it is also important to consider limitations with regard to internal validity of the presented findings. Selection bias is a common but important problem in dyadic field studies, and surveys (in experiments) have general limitations when it comes to establishing causal mechanisms. For instance, Study 4 , we demonstrate the theoretical mechanism that underlies our central finding by showing that the conditional effect of authenticity on service performance can be explained by inferred deception. A notable limitation of this study is that both mediators and the dependent variable were measured using attitudinal, self-reported scales. Further research should shine further light on this mechanism by experimentally manipulating the mediators to strengthen the causal evidence for mediated moderation.

\section{Conclusion}

Despite growing managerial interest in FLE behavior, and display authenticity specifically, customer heterogeneity in terms of reactions to authentic displays has received little attention. Literature on emotions as social information (van Kleef 2014) posits that such heterogeneity can be explained by customers' motivation. Drawing on regulatory focus theory, we show that customers' prevention motivation decreases service performance when FLEs display inauthentic (cf. authentic) emotions; no such effect exists among promotion-focused customers, which helps address inconsistencies in extant literature. This contingency is manifested in different tip amounts in our field study (Study 1), and it holds whether the prevention focus is a stable individual difference (Studies 1 and 2) or temporary (Studies 3 and 4). The effect pattern is driven by mediation; prevention-focused customers interpret inauthentic emotion displays as more deceptive than do promotion-focused customers. When inauthentic displays are likely, managers can ensure a stronger positive impact on service performance by priming customers' promotion focus in their marketing communications and investing in authenticity training in accordance with their customers' primary regulatory focus.

\section{Appendix}

\section{Methods}

Study I*

Customer Survey

Bill Total (Chi et al. 2011)

What was the bill total (excl. tip)? 
Tip (Chi et al. 2011)

How much did you tip?

Trait Regulatory Focus (Lockwood, Jordan, and Kunda 2002)

In general, I am focused on preventing negative events in my life.

In general, I am focused on achieving positive outcomes in my life

Café Busyness (Grandey et al. 2005)

How crowded was the café during your visit?

Group Size (Chi et al. 2011)

How many people accompanied you to your visit today?

Patronage Frequency (Wang and Groth 2014)

On how many occasions have you been at this café in the past 12 months?

Demographics

Are you male or female?

How old are you?

Employee survey

Authenticity (Yagil 2014)

The emotions I expressed to these customers were genuine.

Demographics

Are you male or female?

How old are you?

\section{Study 2*}

Trait Regulatory Focus (Higgins et al. 2001)

Compared to most people, are you typically unable to get what you want out of life?

Growing up, would you ever "cross the line" by doing things that your parents would not tolerate?

How often have you accomplished things that got you "psyched" to work even harder?

Did you get on your parents' nerves often when you were growing up?

How often did you obey rules and regulations that were established by your parents?

Growing up, did you ever act in ways that your parents thought were objectionable?

Do you often do well at different things that you try?

Not being careful enough has gotten me into trouble at times.

When it comes to achieving things that are important to me, I find that I don't perform as well as I ideally would like to do.

I feel like I have made progress toward being successful in my life.

I have found very few hobbies or activities in my life that capture my interest or motivate me to put effort into them.

Authenticity Manipulation Exemplary stills (Lechner and Paul 2019)
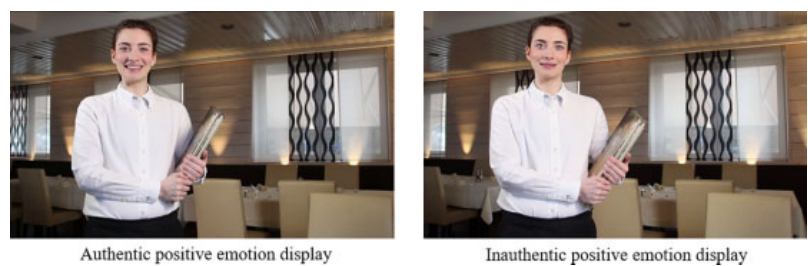

Satisfaction (Burnham, Frels, and Mahajan 2003; Keh et al. 2013)

I am pleased with the overall service provided by the employee.

What I get from my service provider meets what I expect for this type of service.

I am completely satisfied with the experience by the employee.

Display Authenticity Manipulation Check (Côté, Hideg, and van Kleef 2013)

The emotions that the employee was showing were real.

This employee seemed to be pretending, or putting on an act, in this interaction. (r)

Demographics

Are you male or female?

How old are you?

What is your occupation?

\section{Study 3}

Regulatory Focus Manipulation (prevention in text, promotion in square brackets; Pham and Avnet 2004)

This first study is about how people's sense of duty and obligations [hopes and goals] evolve over time.

Think about the duties and obligations [hopes and goals] that you had in the past (e.g., as you were growing up). By duties and obligations, we mean the things that you were expected or required to do, your responsibilities, the things you were trusted to do, the things you knew you ought to do. [By hopes and goals, we mean the things you really wanted to achieve or obtain, your aspirations, your dreams.]

Please write at least two of these past duties and obligations [hopes and goals] in the space below.

An example: When I was in junior high, my parents really expected me to have good grades in every single class. They also expected me to take care of my baby sister all the time.

[When I was 17 years old, I wanted to have fun and travel around the world.]

Now think about your duties and obligations [hopes and goals] as they are today. What are the things expected to do now? What are your new responsibilities? What are your commitments, the things you know you ought to do? [What are the things you really want to achieve now, the things you are aspiring to, dreaming of, for the future.]

Please write at least two of these present duties and obligations [hopes and goals] in the space below.

An example: Today, I need to get a job soon because I have to pay back loans and I also feel I need to make my Parents proud of me. [Today I am an MBA student and $I$ hope to have a successful career in investment banking.] 
Display Authenticity Manipulation Exemplary pictures (Lechner and Paul 2019)
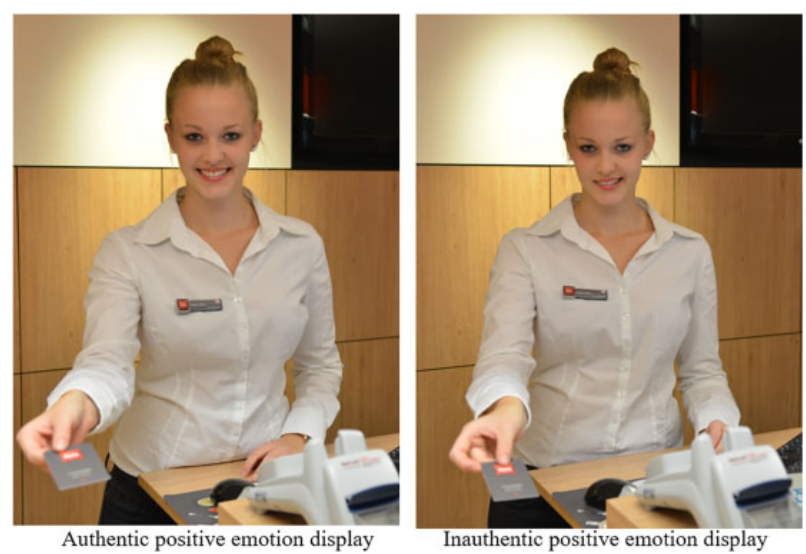

Satisfaction (Burnham, Frels, and Mahajan 2003; Keh et al.

2013)

I am pleased with the overall service provided by the employee.

What I get from my service provider meets what I expect for this type of service.

I am completely satisfied with the experience by the employee.

Display Authenticity Manipulation Check (Côté, Hideg, and

van Kleef 2013)

The emotions that the employee was showing were real.

This employee seemed to be pretending, or putting on an act, in this interaction. (r)

Demographics

Are you male or female?

How old are you?

What is your occupation?

Temporary Regulatory Focus (Study 3 pretest; Pham and Avnet 2004)

At this moment, I want to do whatever I want rather than to do what is right.

At this moment, I want to go wherever my heart takes me rather than to do whatever it takes to keep my promises.

Smile Intensity (Study 3 pretest) (Barr and Kleck 1995)

The smile of the FLE was extreme.

\section{Study 4}

Positive Display Authenticity Manipulation Exemplary Pictures

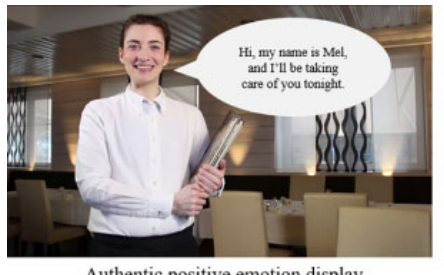

Authentic positive emotion display

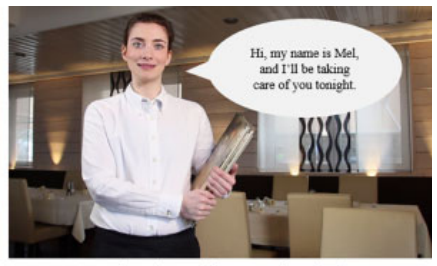

Inauthentic positive emotion display
Regulatory Focus Manipulation (excerpt of text presented in speech balloons; prevention condition in text, promotion condition in square brackets; adapted from Lee and Aaker 2004)
Have you noticed the recent addition of Purple Grape Juice to our menu?

Preliminary medical research suggests that drinking purple grape juice may contribute to healthy cardiovascular function. Growing evidence suggests that diets rich in antioxidants may reduce the risk of some cancers and heart disease. [Preliminary medical research suggests that drinking purple grape juice may contribute to the creation of greater energy! Growing evidence suggests that diets rich in Vitamin $\mathrm{C}$ and iron lead to higher energy levels.]

Satisfaction (Burnham, Frels, and Mahajan 2003; Keh et al. 2013)

I am pleased with the overall service provided by the employee.

What I get from my service provider meets what I expect for this type of service.

I am completely satisfied with the experience by the employee.

Inferred Deception (Darke and Ritchie 2007)

This employee seemed truthful. (r)

This employee seemed honest. (r)

This employee seemed deceptive.

This employee seemed misleading.

Post-Delivery Positive Affect (Hennig-Thurau et al. 2006)

At this moment, I feel elated.

At this moment, I feel peppy.

At this moment, I feel enthusiastic.

At this moment, I feel excited.

Display Authenticity Manipulation Check (Côté, Hideg, and van Kleef 2013)

The emotions that the employee was showing were real.

This employee seemed to be pretending, or putting on an act, in this interaction. (r)

Regulatory Focus Prime Manipulation Check (Lee and Aaker 2004)

The juice helps keeping arteries unclogged.

The juice is healthy to drink.

Demographics

Are you male or female?

How old are you?

What is your occupation?

*All items in Studies 1 and 2 were translated to German and back-translated to English to ensure equivalence. German items are available on request. Studies 3 and 4, conducted in the United Kingdom, used the English-language versions.

\section{Acknowledgments}

The authors thank Michael Paul, E. Tory Higgins, and Maya Rossignac-Milon for their helpful comments on earlier versions of this article, and the anonymous reviewers and special issue editors for their helpful comments and guidance in the review process.

\section{Declaration of Conflicting Interests}

The author(s) declared no potential conflicts of interest with respect to the research, authorship, and/or publication of this article. 


\section{Funding}

The author(s) received no financial support for the research, authorship, and/or publication of this article.

\section{ORCID iD}

Andreas T. Lechner (D) https://orcid.org/0000-0001-8804-3723

\section{Supplemental Material}

Supplemental material for this article is available online.

\section{Notes}

1. We also analyzed individual effects of prevention and promotion focus and their respective interactions with display authenticity. The results revealed no main effects, though the interaction effect of authenticity and prevention was significant $(p<.05)$ and yielded the same effect pattern as in the predominance analysis; the interaction of authenticity and promotion was insignificant. When we included a three-way interaction of authenticity, prevention, and promotion, the interaction was not significant. The results again remained unchanged if we added the controls.

2. The focal interaction effect remained significant $(p<.05)$ when we included these items too.

3. As in Study 1, we analyzed the individual effects of prevention and promotion focus and their respective interactions with display authenticity. The results revealed positive main effects of authenticity and promotion but not prevention. The interaction effect of authenticity and prevention was significant $(p<.05)$, yielding the same effect pattern as the predominance analysis, and the interaction of authenticity and promotion was insignificant. The threeway interaction of authenticity, prevention, and promotion was not significant. The results remained unchanged when we included customer gender as a control variable.

4. Wang et al. (2017) investigate the role of epistemic, rather than regulatory focus, motivations, for authentic displays and show that the effect of service quality due to authenticity, though not the effect of authenticity itself, is moderated by epistemic motivations. In addition to affirming the claim in emotion as social information theory that the effects of authenticity depend on the observer's motivation (van Kleef 2009, 2014), we can combine our results with Wang et al.'s (2017) to establish that it is regulatory focus, rather than epistemic motivations, that moderate the effects of authenticity. Epistemic motivations are not irrelevant but moderate only downstream effects (Wang et al. 2017).

\section{References}

Andrzejewski, Susan A. and Emily C. Mooney (2016), "Service with a Smile: Does the Type of Smile Matter?," Journal of Retailing and Consumer Services, 29 (1), 135-141.

$\mathrm{Au}, \mathrm{Al}$ K. C. and Nicholas C. Q. Wong (2019), "Perceived Deception in Negotiation: Consequences and the Mediating Role of Trust," The Journal of Social Psychology, 159 (4), 459-473.

Barr, Carol L. and Robert E. Kleck (1995), "Self-Other Perception of the Intensity of Facial Expressions of Emotion: Do We Know What We Show?," Journal of Personality and Social Psychology, 68 (4), 608-618.
Beersma, Bianca, Astrid C. Homan, Gerben A. van Kleef, and Carsten K. W. de Dreu (2013), "Outcome Interdependence Shapes the Effects of Prevention Focus on Team Processes and Performance," Organizational Behavior and Human Decision Processes, 121 (2), 194-203.

Best Buy (2018), "Culture," (accessed March 27, 2018), [available at http://www.bestbuy-jobs.com/culture/].

Bird, Jon (2018), "The Robot Restaurant Revolution: 'Jetsons-Like' Dream Or Automation Nightmare," (accessed September 29, 2018), [available at https://www.forbes.com/sites/jonbird1/2018/ 09/04/the-robot-restaurant-revolution-jetsons-like-dream-or-auto mation-nightmare/\#4af25cf36cef].

Bond, Charles F., Adnan Omar, Urvashi Pitre, Brian R. Lashley, Lynn M. Skaggs, and C. T. Kirk (1992), "Fishy-Looking Liars: Deception Judgment From Expectancy Violation," Journal of Personality and Social Psychology, 63 (6), 969-977.

Brach, Simon, Gianfranco Walsh, Thorsten Hennig-Thurau, and Markus Groth (2015), "A Dyadic Model of Customer Orientation: Mediation and Moderation Effects," British Journal of Management, 26 (2), 292-309.

Brockner, Joel and E. Tory Higgins (2001), "Regulatory Focus Theory: Implications for the Study of Emotions at Work," Organizational Behavior and Human Decision Processes, 86 (1), 35-66.

Burnham, Thomas A., Judy K. Frels, and Vijay Mahajan (2003), "Consumer Switching Costs: A Typology, Antecedents, and Consequences," Journal of the Academy of Marketing Science, 31 (2), 109-126.

Chi, Nai-Wen and Alicia A. Grandey (2019), "Emotional Labor Predicts Service Performance Depending on Activation and Inhibition Regulatory Fit," Journal of Management, 45 (2), 673-700.

Chi, Nai-Wen and Pei Chi Chen (2019), "Relationship Matters: How Relational Factors Moderate the Effects of Emotional Labor on Long-Term Customer Outcomes," Journal of Business Research, 95 (2), 277-291.

Chi, Nai-Wen, Alicia A. Grandey, Jennifer A. Diamond, and Kathleen Royer Krimmel (2011), "Want a Tip? Service Performance as a Function of Emotion Regulation and Extraversion," Journal of Applied Psychology, 96 (6), 1337-1346.

Côté, Stéphane, Ivona Hideg, and Gerben A. van Kleef (2013), "The Consequences of Faking Anger in Negotiations," Journal of Experimental Social Psychology, 49 (3), 453-463.

Dahling, Jason J. and Hazel-Anne M. Johnson (2013), "Motivation, Fit, Confidence, and Skills. How Do Individual Differences Influence Emotional Labor?," in Emotional Labor in the 21st Century: Diverse Perspectives on Emotion Regulation at Work, A. A. Grandey, J. M. Diefendorff and D. E. Rupp, eds. New York: Routledge, 57-78.

Darke, Peter R. and Robin J. B. Ritchie (2007), "The Defensive Consumer: Advertising Deception, Defensive Processing, and Distrust," Journal of Marketing Research, 44 (1), 114-127.

Das, Gopal, Amaradri Mukherjee, and Ronn J. Smith (2018), "The Perfect Fit: The Moderating Role of Selling Cues on Hedonic and Utilitarian Product Types," Journal of Retailing, 94 (2), 203-216.

Diefendorff, James M., Meredith H. Croyle, and Robin H. Gosserand (2005), "The Dimensionality and Antecedents of Emotional Labor Strategies," Journal of Vocational Behavior, 66 (2), 339-357. 
Enders, Craig K. and Davood Tofighi (2007), "Centering Predictor Variables in Cross-Sectional Multilevel Models: A New Look at an Old Issue," Psychological Methods, 12 (2), 121-138.

Faddegon, Krispijn, Daan Scheepers, and Naomi Ellemers (2008), "If We Have the Will, There Will Be a Way: Regulatory Focus as a Group Identity," European Journal of Social Psychology, 38 (5), 880-895.

Fornell, Claes and David F. Larcker (1981), "Evaluating Structural Equation Models with Unobservable Variables and Measurement Error," Journal of Marketing Research, 18 (1), 39-50.

Freitas, Antonio L. and E. Tory Higgins (2002), "Enjoying GoalDirected Action: The Role of Regulatory Fit," Psychological Science, 13 (1), 1-6.

Gamache, Daniel L., Gerry McNamara, Michael J. Mannor, and Russell E. Johnson (2013), "Motivated to Acquire? The Impact of CEO Regulatory Focus on Firm Acquisitions," Academy of Management Journal, 58 (4), 1261-1282.

Gamez-Djokic, Monica and Daniel Molden (2016), "Beyond Affective Influences on Deontological Moral Judgment: The Role of Motivations for Prevention in the Moral Condemnation of Harm," Personality and Social Psychology Bulletin, 42 (11), 1522-1537.

Gountas, Sandra, Michael T. Ewing, and John I. Gountas (2007), "Testing Airline Passengers' Responses to Flight Attendants' Expressive Displays: The Effects of Positive Affect," Journal of Business Research, 60 (1), 81-83.

Grandey, Alicia A., Lawrence Houston, and Derek R. Avery (2018), "Fake It to Make It? Emotional Labor Reduces the Racial Disparity in Service Performance Judgments," Journal of Management, 45 (5), 2163-2192.

Grandey, Alicia A. and Allison S. Gabriel (2015), "Emotional Labor at a Crossroads: Where Do We Go from Here?," Annual Review of Organizational Psychology and Organizational Behavior, 2 (1), 323-349.

Grandey, Alicia A., James M. Diefendorff, and Deborah E. Rupp (2013), "Bringing Emotional Labor into Focus: A Review and Integration of Three Research Lenses," in Emotional Labor in the 21st Century: Diverse Perspectives on Emotion Regulation at Work, A. A. Grandey, J. M. Diefendorff, and D. E. Rupp, eds. New York: Routledge, 3-27.

Grandey, Alicia A., Glenda M. Fisk, Anna S. Mattila, Karen J. Jansen, and Lori A. Sideman (2005), "Is 'Service With a Smile' Enough? Authenticity of Positive Displays During Service Encounters," Organizational Behavior and Human Decision Processes, 96 (1), 38-55.

Grandey, Alicia A. (2003), "When 'The Show Must Go On': Surface Acting and Deep Acting as Determinants of Emotional Exhaustion and Peer-Rated Service Delivery," Academy of Management Journal, 46 (1), 86-96.

Gross, James J. (1998), “The Emerging Field of Emotion Regulation: An Integrative Review," Review of General Psychology, 2 (3), 271-299.

Groth, Markus, Yu Wu, Helena Nguyen, and Anya Johnson (2019), "The Moment of Truth: A Review, Synthesis, and Research Agenda for the Customer Service Experience," Annual Review of Organizational Psychology and Organizational Behavior, 6 (1), 89-113.
Groth, Markus, Thorsten Hennig-Thurau, and Gianfranco Walsh (2009), "Customer Reactions to Emotional Labor: The Roles of Employee Acting Strategies and Customer Detection Accuracy," Academy of Management Journal, 52 (5), 958-974.

Gunnery, Sarah D. and Judith A. Hall (2014), "The Duchenne Smile and Persuasion," Journal of Nonverbal Behavior, 38 (2), 181-194.

Hard Rock Cafe International (2017), "Culture," (accessed Jan 9, 2017), [available at https://www.hardrockhotels.com/culture.htm].

Hayes, Andrew F. (2013), Introduction to Mediation, Moderation, and Conditional Process Analysis: A Regression-Based Approach. New York: Guilford Press.

Hennig-Thurau, Thorsten, Markus Groth, Michael Paul, and Dwayne D. Gremler (2006), "Are All Smiles Created Equal? How Emotional Contagion and Emotional Labor Affect Service Relationships," Journal of Marketing, 70 (3), 58-73.

Higgins, E. Tory and James F. M. Cornwell (2016), "Securing Foundations and Advancing Frontiers: Prevention and Promotion Effects on Judgment \& Decision Making," Organizational Behavior and Human Decision Processes, 136 (2016), 56-67.

Higgins, E. Tory (2012), Beyond Pleasure and Pain: How Motivation Works. New York: Oxford University Press.

Higgins, E. Tory, Antonio Pierro, and W. Kruglanski (2008), "Rethinking Culture and Personality: How Self-regulatory Universals Create Cross-cultural Differences," in Handbook of Motivation and Cognition Across Cultures, R. M Sorrentino, ed. New York: Guilford Press, 161-190.

Higgins, E. Tory, Ronald S. Friedman, Robert E. Harlow, Lorraine Chen Idson, Ozlem N. Ayduk, and Amy Taylor (2001), "Achievement Orientations from Subjective Histories of Success: Promotion Pride versus Prevention Pride," European Journal of Social Psychology, 31 (1), 3-23.

Higgins, E. Tory (1998), "Promotion and Prevention: Regulatory Focus as a Motivational Principle," Advances in Experimental Social Psychology, 30 (1998), 1-46.

Higgins, E. Tory, James Shah, and Ronald Friedman (1997), "Emotional Responses to Goal Attainment: Strength of Regulatory Focus as Moderator," Journal of Personality and Social Psychology, 72 (3), 515-525.

Higgins, E. Tory, Christopher J. R. Roney, Ellen Crowe, and Charles Hymes (1994), "Ideal versus Ought Predilections for Approach and Avoidance: Distinct Self-Regulatory Systems," Journal of Personality and Social Psychology, 66 (2), 276-286.

Higgins, E. Tory, Ruth Klein, and Timothy Strauman (1985), "SelfConcept Discrepancy Theory: A Psychological Model for Distinguishing among Different Aspects of Depression and Anxiety," Social Cognition, 3 (1), 51-76.

Houston, Lawrence, Alicia A. Grandey, and Katina Sawyer (2018), "Who Cares If 'Service with a Smile' Is Authentic? An Expectancy-Based Model of Customer Race and Differential Service Reactions," Organizational Behavior and Human Decision Processes, 144 (1), 85-96.

Huang, Francis L. (2018), "Multilevel Modeling Myths," School Psychology Quarterly, 33 (3), 492-499.

Huang, Francis L. (2016), "Alternatives to Multilevel Modeling for the Analysis of Clustered Data Alternatives to Multilevel 
Modeling for the Analysis of Clustered Data," Journal of Experimental Eeducation, 84 (1), 175-196.

Huang, Perng-Fei and Chai-Wen Dai (2010), "The Impacts of Emotional Contagion and Emotional Labor Perception on Employees' Service Performance," International Journal of Electronic Business Management, 8 (1), 68-79.

Hulland, John (1999), "Use of Partial Least Squares (PLS) in Strategic Management Research: A Review of Four Recent Studies," Strategic Management Journal, 20 (2), 195-204.

Hülsheger, Ute R., Jonas W. B. Lang, Anna F. Schewe, and Fred R. H. Zijlstra (2015), "When Regulating Emotions at Work Pays Off: A Diary and an Intervention Study on Emotion Regulation and Customer Tips in Service Jobs," Journal of Applied Psychology, 100 (2), 263-277.

Hülsheger, Ute R. and Anna F. Schewe (2011), “On the Costs and Benefits of Emotional Labor: A Meta-Analysis of Three Decades of Research," Journal of Occupational Health Psychology, 16 (3), 361-389.

Idson, Lorraine Chen, Nira Liberman, and E. Tory Higgins (2000), "Distinguishing Gains from Nonlosses and Losses from Nongains: A Regulatory Focus Perspective on Hedonic Intensity," Journal of Experimental Social Psychology, 36 (3), 252-274.

Jehn, Karen A. and Elizabeth D. Scott (2008), "Perceptions of Deception: Making Sense of Responses to Employee Deceit," Journal of Business Ethics, 80 (2), 327-347.

Kammeyer-Mueller, John D., Alex L. Rubenstein, David M. Long, Michael A. Odio, Brooke R. Buckman, Yiwen Zhang, and Marie D. K. Halvorsen-Ganepola (2013), "A Meta-Analytic Structural Model of Dispositonal Affectivity and Emotional Labor," Personnel Psychology, 66 (1), 47-90.

Keh, Hean Tat, Run Ren, Sally Rao Hill, and Xuan Li (2013), “The Beautiful, the Cheerful, and the Helpful: The Effects of Service Employee Attributes on Customer Satisfaction," Psychology \& Marketing, 30 (3), 211-226.

Keltner, Dacher and Jonathan Haidt (1999), "Social Functions of Emotions at Four Levels of Analysis," Cognition \& Emotion, 13 (5), 505-521.

Kirmani, Amna and Rui (Juliet) Zhu (2007), "Vigilant Against Manipulation: The Effect of Regulatory Focus on the Use of Persuasion Knowledge," Journal of Marketing Research, 44 (4), 688-701.

Doorn, van, A. Evert, Gerben A. van Kleef, and Joop van der Pligt (2014), 'How Instructors' Emotional Expressions Shape Students' Learning Performance: The Roles of Anger, Happiness, and Regulatory Focus," Journal of Experimental Psychology: General, 143 (3), 980-984.

Kleef, van and A. Gerben (2014), "Understanding the Positive and Negative Effects of Emotional Expressions in Organizations: EASI Does It," Human Relations, 67 (9), 1145-1164.

Kleef, van, A. Gerben, Carsten K. W. de Dreu, and Antony S. R. Manstead (2010), “An Interpersonal Approach to Emotion in Social Decision Making: The Emotions as Social Information Model," Advances in Experimental Social Psychology, 42 (2010), 45-96.

van Kleef, Gerben A. (2009), "How Emotions Regulate Social Life: The Emotions as Social Information (EASI) Model," Current Directions in Psychological Science, 18 (3), 184-188.
Laros, Fleur J. M. and Jan-Benedict E. M. Steenkamp (2005), "Emotions in Consumer Behavior: A Hierarchical Approach," Journal of Business Research, 58 (10), 1437-1445.

Lavan, Nadine, César F. Lima, Hannah Harvey, Sophie K. Scott, and Carolyn Mcgettigan (2015), "I Thought that I Heard You Laughing: Contextual Facial Expressions Modulate the Perception of Authentic Laughter and Crying," Cognition \& Emotion, 29 (5), 935-944.

Lechner, Andreas T. and Michael Paul (2019), "Is this Smile for Real? The Role of Affect and Thinking Style in Customer Perceptions of Frontline Employee Emotion Authenticity," Journal of Business Research, 94 (1), 195-208.

Lee, Angela Y. and Jennifer L. Aaker (2004), "Bringing the Frame Into Focus: The Influence of Regulatory Fit on Processing Fluency and Persuasion," Journal of Personality and Social Psychology, 86 (2), 205-218.

Liu, Yongmei, L. Melita Prati, Pamela L. Perrewé, and Gerald R. Ferris (2008), “The Relationship Between Emotional Resources and Emotional Labor: An Exploratory Study," Journal of Applied Social Psychology, 38 (10), 2410-2439.

Lockwood, Penelope, Christian H. Jordan, and Ziva Kunda (2002), "Motivation by Positive or Negative Role Models: Regulatory Focus Determines Who Will Best Inspire Us," Journal of Personality and Social Psychology, 83 (4), 854-864.

Lynn, Michael, George M. Zinkhan, and Judy Harris (1993), "Consumer Tipping: A Cross-Country Study," Journal of Consumer Research, 20 (3), 478-488.

Maas, Cora J. M. and Joop J. Hox (2004), “The Influence of Violations of Assumptions on Multilevel Parameter Estimates and Their Standard Errors," Computational Statistics and Data Analysis, 46 (3), 427-440.

Matthews, Russell A. and Alyssa Mitchell Gibbons (2016), "Developing and Investigating the Use of Single-Item Measures in Organizational Research," Journal of Occupational Health Psychology, 21 (1), 3-23.

Mesmer-Magnus, Jessica R., Leslie A. DeChurch, and Amy Wax (2012), "Moving Emotional Labor Beyond Surface and Deep Acting: A Discordance-Congruence Perspective," Organizational Psychology Review, 2 (1), 6-53.

Motyka, Scott, Dhruv Grewal, Nancy M. Puccinelli, Anne L. Roggeveen, Tamar Avnet, Ahmad Daryanto, de Ruyter Ko, and Martin Wetzels (2014), "Regulatory Fit: A Meta-Analytic Synthesis," Journal of Consumer Psychology, 24 (3), 394-410.

Oliver, Richard L. (2010), Satisfaction: A Behavioral Perspective on the Consumer. New York: ME Sharpe.

Paul, Michael, Thorsten Hennig-Thurau, and Markus Groth (2015), "Tightening or Loosening the 'Iron Cage'? The Impact of Formal and Informal Display Controls on Service Customers," Journal of Business Research, 68 (5), 1062-1073.

Perdue, Barbara C. and John O. Summers (1986), "Checking the of Manipulations in Marketing Experiments," Journal of Marketing Research, 23 (4), 317-326.

Pham, Michel Tuan and Tamar Avnet (2004), "Ideals and Oughts and the Reliance on Affect Versus Substance in Persuasion," Journal of Consumer Research, 30 (4), 503-518. 
Prati, L. Melita, Yongmei Liu, Pamela L. Perrewe, and Gerald R. Ferris (2009), "Emotional Intelligence as Moderator of the Surface Acting - Strain Relationship," Journal of Leadership \& Organizational Studies, 15 (4), 368-380.

Pula, Kacy, Craig D. Parks, and Carolyn F. Ross (2014), "Regulatory Focus and Food Choice Motives. Prevention Orientation Associated with Mood, Convenience, and Familiarity," Appetite, 78 (C), 15-22.

Riquelme, Isabel P., Sergio Román, and Dawn Iacobucci (2016), "Consumers' Perceptions of Online and Offline Retailer Deception: A Moderated Mediation Analysis," Journal of Interactive Marketing, 35 (C), 16-26.

Rust, Roland T. and Bruce Cooil (1994), "Reliability Measures for Qualitative Data: Theory and Implications," Journal of Marketing Research, 31 (1), 1-14.

Schuster, Jahneil (2012), "Kroger Employee Manual," (accessed January 10, 2017), [available at https://jahneilschuster.weebly.com/ uploads/1/4/5/3/14534778/kroger.pdf].

SDA (Shop, Distributive and Allied Employees' Association) Union (2018), "Working in Fast Food Doesn't Put Us Below You," (accessed April 3, 2019), [available at https://www.youtube.com/ watch?v=QBX9KAej5MM].

Sengupta, Jaideep and Rongrong Zhou (2007), "Understanding Impulsive Eaters' Choice Behaviors: The Motivational Influences of Regulatory Focus," Journal of Marketing Research, 44 (2), 297-308.

Skinner, Martin and Brian Mullen (1991), "Facial Asymmetry in Emotional Expression: A Meta-Analysis of Research," British Journal of Social Psychology, 30 (2), 113-124.

Sliter, Michael, Steve Jex, Katherine Wolford, and Joanne McInnerney (2010), "How Rude! Emotional Labor as a Mediator Between Customer Incivility and Employee Outcomes," Journal of Occupational Health Psychology, 15 (4), 468-481.

Solomon, Micah (2015), "Your Customer Service Is Your Branding: The Ritz-Carlton Case Study," (accessed January 9, 2017), [available at http://www.forbes.com/sites/micahsolomon/2015/09/24/ your-customer-service-style-is-your-brand-the-ritz-carlton-casestudy/\#592b251b1b8a].

Sporer, Siegfried L. and Barbara Schwandt (2007), "Moderators of Nonverbal Indicators of Deception: A Meta-Analytic Synthesis," Psychology, Public Policy, and Law, 13 (1), 1-34.

Taylor, Bill (2013), "Pret a Manger Wants Happy Employees-And That's OK," Harvard Business Review, (accessed March 26, 2018), [available at https://hbr.org/2013/11/pret-a-manger-wantshappy-employees-and-thats-ok].

Walmart (2018), "Working at Walmart," (accessed March 25, 2018), [available at https://corporate.walmart.com/our-story/working-atwalmart].

Wang, Gang, Scott E. Seibert, and Terry L. Boles (2011), "Synthesizing What We Know and Looking Ahead: A Meta-Analytical Review of 30 Years of Emotional Labor Research," in Research on Emotion in Organizations, C. E. J. Härtel, N. M. Ashkanasy and W. Zerbe, eds. Bingley, UK: Emerald Group, 15-43.
Wang, Karyn L. and Markus Groth (2014), "Buffering the Negative Effects of Employee Surface Acting: The Moderating Role of Employee-Customer Relationship Strength and Personalized Services," Journal of Applied Psychology, 99 (2), 341-350.

Wang, Ze, Surendra N. Singh, J. Li Yexin, Sanjay Mishra, Maureen Ambrose, and Monica Biernat (2017), "Effects of Employees' Positive Affective Displays on Customer Loyalty Intentions: An Emotions-as-Social-Information Perspective," Academy of Management Journal, 60 (1), 109-129.

Werth, Lioba and Jens Foerster (2007), "How Regulatory Focus Influences Consumer Behavior Consumer," European Journal of Social Psychology, 37 (1), 33-51.

Winterheld, Heike A. and Jeffry A. Simpson (2011), "Seeking Security or Growth: A Regulatory Focus Perspective on Motivations in Romantic Relationships," Journal of Personality and Social Psychology, 101 (5), 935-954.

Yagil, Dana and Moran Shnapper-Cohen (2016), "When Authenticity Matters Most: Physicians' Regulation of Emotional Display and Patient Satisfaction," Patient Education and Counseling, 99 (10), 1694-1698.

Yagil, Dana (2014), "Trust in the Supervisor and Authenticity in Service Roles,” Journal of Service Management, 25 (3), 411-426.

Yen, Chih Long, Shu He Chao, and Chun Yu Lin (2011), "Field Testing of Regulatory Focus Theory," Journal of Applied Social Psychology, 41 (6), 1565-1581.

Zeithaml, Valarie, Mary Jo Bitner, and Dwayne D. Gremler (2013), Services Marketing: Integrating Customer Focus Across the Firm. New York: McGraw Hill Irwin.

Zhou, Rongrong and Michel T. Pham (2004), "Promotion and Prevention across Mental Accounts: When Financial Products Dictate Consumers' Investment Goals," Journal of Consumer Research, 31 (June), 125-135.

\section{Author Biographies}

Andreas T. Lechner is a research fellow at the University of Augsburg, Germany, where he previously earned his $\mathrm{PhD}$ in marketing with a thesis on boundary conditions of customer reactions to employee display authenticity. His work has been published in the Journal of Business Research and the Journal of Services Marketing. His research interests are in services marketing, frontline employees, emotion regulation, and marketplace discrimination.

Frank Mathmann is a senior lecturer at the Queensland University of Technology in Brisbane, Australia and a visiting scholar at the Higgins Lab of Columbia University. He holds a PhD in marketing from the University of New South Wales and has published his research in the Journal of Retailing, the Personality and Social Psychology Bulletin, and the European Journal of Marketing. His research interests are in consumer self-regulation, value perceptions, and choice. 